\title{
Variations in the Numbers of Phalangeal Bones in the Four-toed Salamander, Hynobius tenuis (Amphibia: Hynobiidae), from Two Localities in Toyama Prefecture, Central Japan
}

\author{
By \\ Hisao NAMBU \\ Toyama Science Museum, Toyama 939, and Graduate School of Science and Technology Niigata University, Niigata, \\ 950-21 Japan \\ - Received for Publication, November 18, $1994-$ \\ Key Words: Salamander, Hynobius tenuis, Phalangeal Bone, Variation

\begin{abstract}
Summary: Variations in the numbers of phalangeal bones in the fingers (I to IV) and toes (I to V) of specimens of Hynobius tenuis collected from two localities (Ashikuraji and Arimine) in Toyama Prefecture, Central Japan, were recorded. In the case of fingers of fore limbs, eight phalangeal formulas were distinguished, and in the case of toes of hind limbs, ten phalangeal formulas were recognized. In the fingers of specimens from Ashikuraji, the predominant formulas were 2-2-3$2(40 \%)$ and 2-2-3-1 (32\%). In specimens from Arimine, 2-2-3-2 was predominant $(75 \%)$. In toes, the predominant formula was 2-2-3-2-0 $(96 \%)$ for Ashikuraji and $71 \%$ for Arimine. The maximal number of phalangeal bones, 2-2-3-3-2, found in the toes of specimens from Arimine seems to represent the fundamental formula in hynobiid salamanders. The predominant formula, 2-2-3-2-( ${ }^{-}$, observed in the two populations may have been derived from the fundamental formula by degeneration of the phalangeal bones in the fourth and the fifth toes. The reason why phalangeal bones were
\end{abstract} \\ degenerated in this species is discussed from an ecological viewpoint of body growth.
}

In some species of salamanders belonging to the genus Plethodon, the numbers of phalangeal bones vary, including reductions in the number, even within the same species (Hanken 1983; Alberch and Gale 1985; Hanken and Dinsmore 1986; Dwyer and Hanken 1989). On the other hand, several genera (Hynobius, Batrachuperus and Salamandrella), belonging to the family Hynobiidae, have four toes on the hind limb (Dunn 1923, 1927; Sato 1943; Nakamura and Ueno 1963; Thorn 1968; Zhao et al. 1988). However, it has been suggested that these hynobiid salamanders originally had five toes. Therefore, it was suggested that an examination of the numbers of phalangeal bones in each finger and toe, and in the fifth toe in particular, may be useful for studying degeneration of phalangeal bones in hynobiid species.

Recently, a new species of the four-toed salamander, Hynobius tenuis, found in the mountainous areas of Central Japan, was described (Nambu 1991). This species seems to be useful for investigating the degeneration in the number of phalangeal bones, since there are some variants with a fifth toe (Nambu 1991). In the present study, variations of the numbers of phalangeal bones were examined in specimens of $H$. tenuis collected from two localities.

\section{Materials and Methods}

Adult specimens of $\boldsymbol{H}$. tenuis were collected from two areas of Toyama Prefecture. One locality was Arimine (Ooyama-machi; $1,390 \mathrm{~m}$ in altitude). In this area, 15 individual males were examined (mean snout-vent length (SVL), $53.2 \mathrm{~mm}$; range, $46.9-54.7 \mathrm{~mm}$ ). The other locality was Ashikuraji (Tateyama-machi; $900 \mathrm{~m}$ in altitude). In this area, 11 males (mean SVL, $50.0 \mathrm{~mm}$; range, $46.1-56.0 \mathrm{~mm}$ ) and 14 females (mean SVL, $52.6 \mathrm{~mm}$; range, 50.7$54.1 \mathrm{~mm}$ ) were collected. The former locality is approximately $14 \mathrm{~km}$ from the latter. All specimens were deposited at the Toyama Science Museum, Toyama Prefecture, Japan.

To count the numbers of phalangeal bones, a soft X-ray apparatus (Type EMB; Softex Co., Japan) was used. Furthermore, the presence of metacarpi and metatarsi was also examined even though these bones were not included in the definition of the phalange. The numerical data obtained from males and females were pooled. However, numbers of bones in the right limbs and the left limbs were recorded separately, since asymmetric specimens in terms of both fingers and toes were observed. The data were summarized as phalangeal formulas. 


\section{Results}

In specimens of $H$. tenuis collected from two localities, numbers of phalangeal bones in the fingers and toes varied considerably. The formulas for the phalangeal bones are listed in Table 1 , in which numbers of bones on the right side and the left side were pooled. In the case of fingers, seven and six formulas were recognized in the specimens from Ashikuraji and Arimine, respectively. In the former group, specimens with the formulas 2-2-3-2 and 2-2$3-1$ were predominant $(40 \%$ and $32 \%$, Figs. $1 \mathrm{~A}$ and 1B). In the latter group, specimens with the formula 2-2-3-2 were more prevalent (75\%). In both localities, the formula that most frequently described the phalangeal bones, was also 2-2-3-2.

In the case of toes, variations in the formulas for the phalangeal bones were greater for Arimine than for Ashikuraji (Table 1). In specimens from these two localities, three and eight formulas were recognized, respectively. In both cases, specimens with the formula $2-2-3-2-0^{-}$were predominant $(96 \%$ and $71 \%$, respectively; Fig. $2 \mathrm{~F}$ ). The maximal numbers of phalangeal bones were represented by the formula 2-2-3-3-0 (Fig. 2C) in the former locality and 2-2-33-2 (Fig. 2A) in the latter. Only two specimens with a fifth toe were found among those from Arimine. The phalangeal formulas of these specimens were as follows. In one specimen, phalanges and metatarsi were present in the fifth toe, and the phalangeal formulas of the five toes were 2-2-3-2-1 (right) and 2-2-3-3-2 (left). The other specimen had the metatarsus in the fifth toe, and the phalangeal formulas were $2-2-3-3-0^{+}$(right) and $2-2-3-2-0^{+}$(left). In this specimen, the fifth toe was visible externally as a
Table 1. The variations in the phalangeal formulas for the fingers and toes of $H$. tenuis

\begin{tabular}{|c|c|c|}
\hline \multirow{2}{*}{$\begin{array}{l}\text { Phalangeal } \\
\text { formula }\end{array}$} & \multicolumn{2}{|c|}{ Locality } \\
\hline & $\begin{array}{c}\text { Ashikuraji } \\
\mathrm{N}=50\end{array}$ & $\begin{array}{c}\text { Arimine } \\
\mathrm{N}=24\end{array}$ \\
\hline \multicolumn{3}{|l|}{ Finger } \\
\hline $2-2-3-2$ & $20(40)$ & $18(75)$ \\
\hline $2-2-3-1$ & $16(32)$ & 1 (4) \\
\hline $2-2-2-2$ & $2(4)$ & 2 (8) \\
\hline $1-2-2-2$ & $0-$ & 1 (4) \\
\hline $2-2-2-1$ & $8(16)$ & 1 (4) \\
\hline $1-2-2-1$ & $2(4)$ & 1 (4) \\
\hline $2-2-2-0^{+}$ & 1 (2) & $0-$ \\
\hline $2-2-1-2$ & 1 (2) & $0-$ \\
\hline \multicolumn{3}{|l|}{ Toe } \\
\hline $2-2-3-3-2$ & - & 1 (4) \\
\hline $2-2-3-2-1$ & - & 1 (4) \\
\hline $2-2-3-3-0^{+}$ & $0-$ & 1 (4) \\
\hline $2-2-3-3-0^{-}$ & $1(2)$ & $0-$ \\
\hline $2-2-3-2-0^{+}$ & $0-$ & 1 (4) \\
\hline $2-2-3-2-0^{-}$ & $48(96)$ & $17(71)$ \\
\hline $1-2-3-2-0^{-}$ & $0-$ & 1 (4) \\
\hline $1-2-3-1-0^{-}$ & 0 & 1 (4) \\
\hline$\overline{1}-2-2-\overline{2}-0^{-}$ & $0-$ & 1 (4) \\
\hline$\overline{1}-1-2-1-0^{-}$ & 1 (2) & $0-$ \\
\hline
\end{tabular}

Note: Sample sizes are given for total numbers of right and left limbs. Parentheses show the ratios (\%) of specimens with each phalangeal formula relative to the total number of specimens in the sample. For fingers, $0^{+}$indicates that the fourth metacarpus was present. For toes, $0^{+}$or $0^{-}$indicates that the fifth metatarsus was present or absent, respectively. Underlining indicates that phalanges were fused.
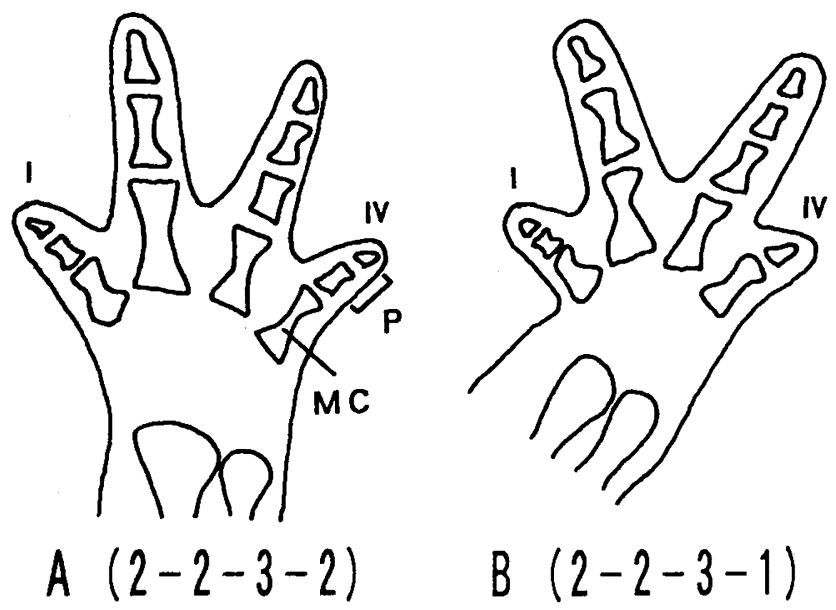
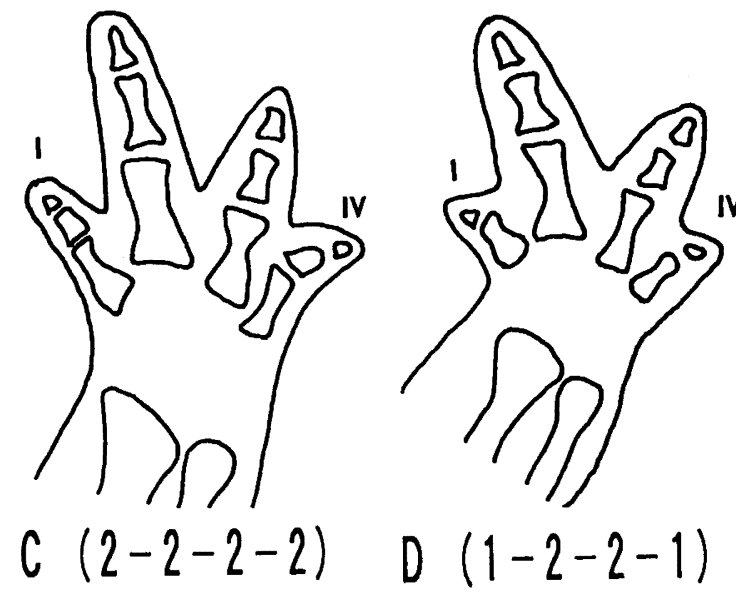

Fig. 1. Four types of phalangeal composition of fingers, representing some of the phalangeal formulas identified for $H$. tenuis. Numbers in parentheses are the numbers of the phalanges from the first (I) to fourth (IV) finger. A shows a hand with the maximal number of phalanges. $\mathrm{B}, \mathrm{C}$ and $\mathrm{D}$ show hands with degenerative phalangeal formulas. Abbreviations: $\mathrm{P}$, phalange; MC, metacarpus. 


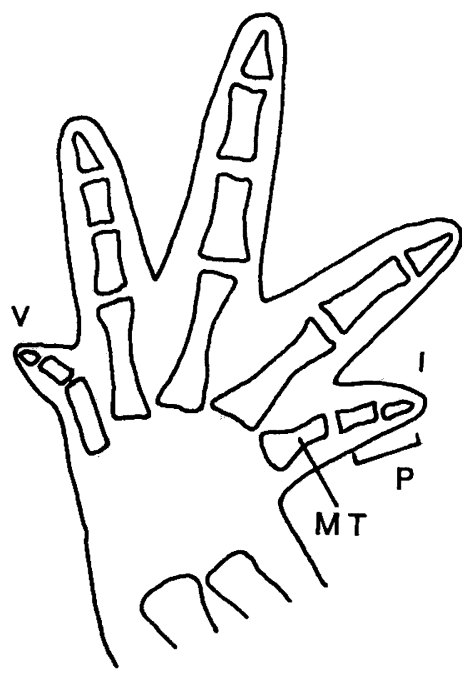

$A(2-2-3-3-2)$

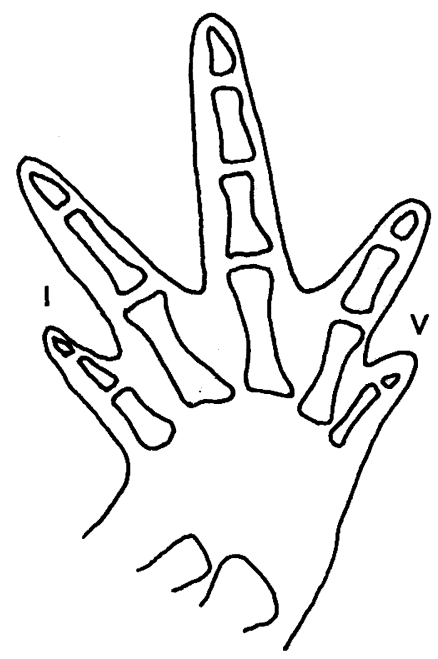

$D(2-2-3-2-1)$
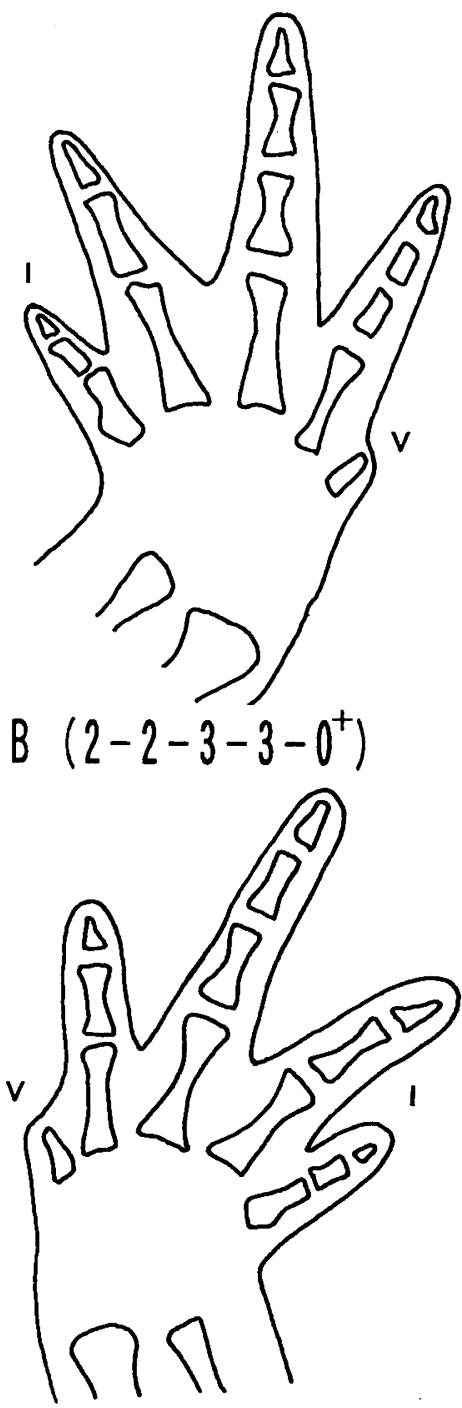

$E\left(2-2-3-2-0^{+}\right)$
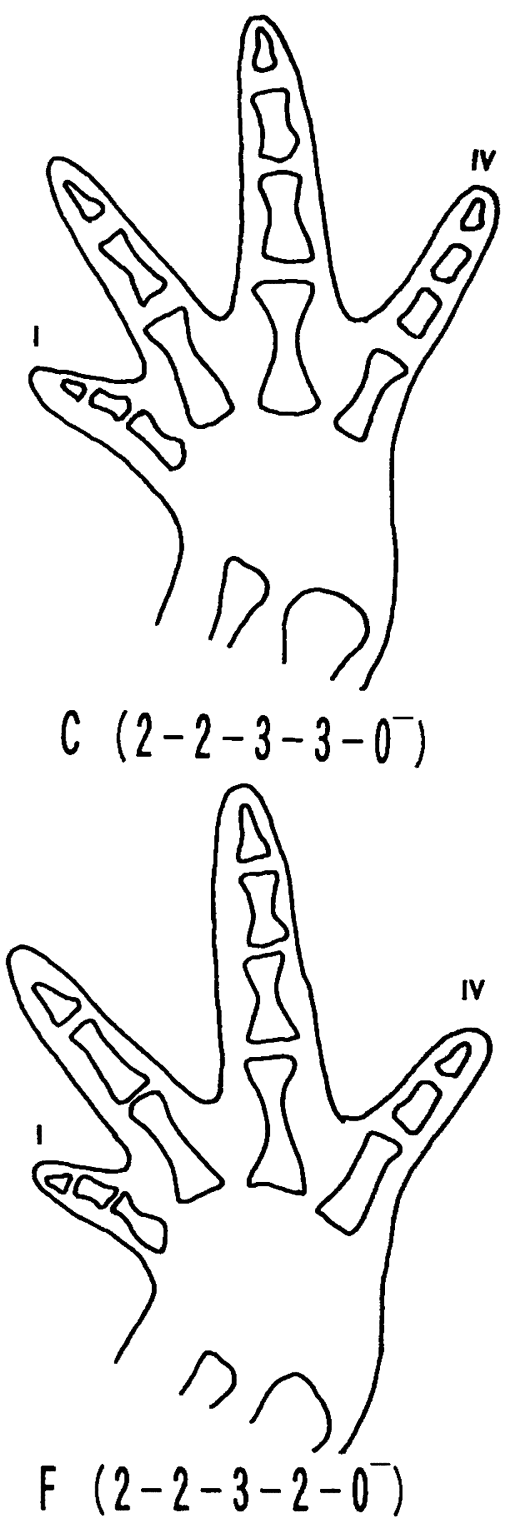

Fig. 2. Six types of phalangeal composition of toes, representing some of the phalangeal formulas identified for $H$. tenuis. Numbers in parentheses are the numbers of phalanges from the first (I) to fifth toe (V) or fourth toe (IV). A shows a foot with the maximal number of phalanges. B, C, D, E and F show feet with degenerative phalangeal formulas. P, Phalange; MT, metatarsus.

small process (Figs. 2B and 2E).

In Table 2, the phalangeal formulas of fingers and toes are listed separately for the right and left sides. In the fingers of specimens from Ashikuraji, seven $(28 \%)$ of 25 specimens had maximal values (2-2-3-2) on both sides. Another seven specimens (28\%) and three additional specimens $(12 \%)$ showed variant formulas on both sides, namely, 2-2-3-1 and 2-2-2-1, respectively. In the remaining eight specimens (32\%), by contrast, the formulas were not coincident for the left and right sides. In the case of fingers of specimens from Arimine, seven (58\%) of 12 specimens showed the maximal values for both sides. The remaining five specimens were asymmetric. In the case of toes, $22(88 \%)$ of 25 specimens from Ashikuraji showed the formula $2-2-3-2-0^{-}$, which was predominant, in both hind limbs. The remaining three specimens $(12 \%)$ were asymmetric. In specimens from Arimine. although seven $(58 \%)$ of 12 showed the same formula, which was predominant, the remaining five $(42 \%)$ were asymmetric.

In Table 3, variations in the numbers of the phalangeal bones in each finger are listed. In the first finger and the second finger, variations in phalangeal bones were rare. In most individuals, these fingers were composed of two phalanges. In the third finger 
and the fourth finger, however, rather large variations were recognized. In Figure 1, four major compositions of phalanges in the third and fourth fingers of the forelimb are shown. In the case of the third finger, specimens that lacked the terminal phalange occurred at a rate of $26 \%$ in Ashikuraji and $21 \%$ in Arimine (Table 3). In specimens from Arimine, the fourth finger was composed of two phalanges in many cases $(88 \%)$. Among specimens from Ashikuraji, 52\% lacked one bone.

Table 2. Coincidence of the phalangeal formulas on the right side and on the left side in H. tenuis

\begin{tabular}{lcc}
\hline \multirow{2}{*}{$\begin{array}{l}\text { Phalangeal } \\
\text { formula }\end{array}$} & \multicolumn{2}{c}{ Locality } \\
\cline { 2 - 3 } & $\begin{array}{c}\text { Ashikuraji } \\
\mathrm{N}=25\end{array}$ & $\begin{array}{c}\text { Arimine } \\
\mathrm{N}=12\end{array}$ \\
\hline $\begin{array}{l}\text { Finger } \\
\text { symmetry }\end{array}$ & & \\
$2-2-3-2$ & $7(28)$ & $7(58)$ \\
$2-2-3-1$ & $7(28)$ & 0 \\
$2-2-2-1$ & $3(12)$ & 0 \\
asymmetry & $8(32)$ & $5(42)$ \\
Toe & & \\
symmetry & & \\
$2-2-3-2-0^{-}$ & $22(88)$ & $7(58)$ \\
asymmetry & $3(12)$ & $5(42)$ \\
\hline
\end{tabular}

Note: Number $(\mathrm{N})$ denotes number of specimens examined. Parentheses show the ratios (\%) of specimens with a given phalangeal formula relative to the total number of specimens in the sample. $0^{-}$indicates that the fifth metatarsus was absent.
In the case of toes, variations in the number of phalangeal bones in each toe were also examined (Table 4). In Figure 2, the six major compositions of phalangeal bones in the fourth toe and the fifth toe are shown. In Arimine, the numbers of phalangeal bones in the first, second and third toes varied little. Variations were recognized, however, in the fourth and fifth toes. Numbers of bones in these toes tended to decrease. In specimen from Arimine, $91 \%$ of specimens lacked a terminal bone in the fourth toe. In the case of the fifth toe, $83 \%$ of specimens lacked both the phalange and the metatarsus. In specimens from Ashikuraji, this tendency was more pronounced. Although the number of phalangeal bones reflected the fundamental formula from the first to the third toe, there were considerably fewer phalangeal bones in the fourth and fifth toes. Most individuals (96\%) lacked a terminal bone in the fourth toe. In the case of the fifth toe, there were no specimens with a phalange or even the metatarsus.

\section{Discussion}

The phalangeal formulas for the fingers in the fore limbs are known for some families. In the family Plethodontidae, in most species, the fundamental formula for the phalangeal bones in the fingers is 1-2-3-2 (Wake 1963, 1966). In two species of the family Salamandridae, Triturus cristanus and Notophthalmus viridescens, the phalangeal formula is 1-2-3-1 (Holder 1983). In Ambystoma mexicanum belonging to the family Ambystomatidae, the formula is 2-2-3-2, which corresponds to the maximal value in salamanders (Holder 1983; Scadding 1991). In $H$. tenuis belonging to the family Hynobiidae, the subject of the present study, the formula was found

Table 3. Frequency of specimens with variations in the numbers of phalangeal bones in each finger in $H$. tenuis

\begin{tabular}{|c|c|c|c|c|c|c|c|c|c|c|}
\hline \multirow{3}{*}{ Locality } & \multirow{3}{*}{$\mathbf{N}$} & \multicolumn{9}{|c|}{ Position of finger/Number of phalange } \\
\hline & & \multicolumn{2}{|c|}{ I } & \multirow{2}{*}{$\frac{\text { II }}{2}$} & \multicolumn{3}{|c|}{ III } & \multicolumn{3}{|c|}{ IV } \\
\hline & & 1 & 2 & & 1 & 2 & 3 & $0^{+}$ & 1 & 2 \\
\hline Ashikuraji & 50 & $\begin{array}{c}2 \\
(4)\end{array}$ & $\begin{array}{c}48 \\
(96)\end{array}$ & $\begin{array}{c}50 \\
(100)\end{array}$ & $\begin{array}{c}1 \\
(2)\end{array}$ & $\begin{array}{c}13 \\
(26)\end{array}$ & $\begin{array}{c}36 \\
(72)\end{array}$ & $\begin{array}{c}1 \\
(2)\end{array}$ & $\begin{array}{c}26 \\
(52)\end{array}$ & $\begin{array}{c}23 \\
(46)\end{array}$ \\
\hline Arimine & 24 & $\begin{array}{c}2 \\
(8)\end{array}$ & $\begin{array}{c}22 \\
(92)\end{array}$ & $\begin{array}{c}24 \\
(100)\end{array}$ & $\begin{array}{c}0 \\
(0)\end{array}$ & $\begin{array}{c}5 \\
(21)\end{array}$ & $\begin{array}{c}19 \\
(79)\end{array}$ & $\begin{array}{c}0 \\
(0)\end{array}$ & $\begin{array}{c}3 \\
(12)\end{array}$ & $\begin{array}{c}21 \\
(88)\end{array}$ \\
\hline
\end{tabular}

Note: Sample sizes are given for the total numbers of right and left limbs. Parentheses show the ratios (\%) of specimens with each phalangeal formula relative to the total number of specimens in the sample. $0^{+}$indicates that the fourth metacarpus was present. 
Table 4. Frequency of specimens with variations in numbers of phalangeal bones in each toe in $H$. tenuis

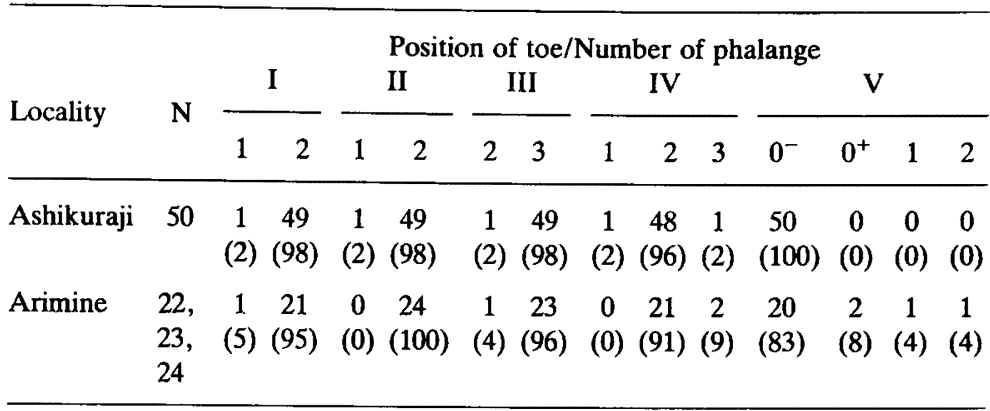

Note: Sample sizes are given for the total numbers of right and left limbs. Parentheses show the ratios (\%) of specimens with each phalangeal formula relative to the total number of specimens in the sample. The data for toes in which phalanges were fused were omitted. $0^{+}$or $0^{-}$indicates that the fifth metatarsus was present or absent, respectively.

to be $2-2-3-2$, the same as that in $A$. mexicanum. In both $H$. nigrescens and $H$. takedai, fundamental phalangeal formulas are 2-2-3-2 (Nambu, unpublished data). Therefore, the phalangeal formula 2-2-3-2 may be the fundamental formula for the genus Hynobius.

The fundamental formulas for the phalangeal bones of the toes in the hind limbs of some hynobiid salamanders have been reported, as follows: 2-2-3-32 in H. lichenatus (Maruyama 1977; Hasumi and Iwasawa 1993); 2-2-3-3-2 in $H$. nigrescens (Alberch and Gale 1985; Hasumi and Iwasawa 1993) and Ranodon sibiricus (Alberch and Gale 1985); and 2-2$3-2-0^{-}$in $H$. hidamontanus (Hasumi and Iwasawa 1993), Salamandrella keyserlingii and Batrachuperus tibetanus (Alberch and Gale 1985). Alberch and Gale (1985) assumed that, in most members of Hynobiidae, the fundamental formula for the phalangeal bones in the toes is 2-2-3-3-2 and that the phalangeal formula $2-2-3-2-0^{-}$in $S$. keyserlingii and $B$. tibetanus, two species of four-toed salamanders, might be derived from the fundamental formula 2-23-3-2. The phalangeal formula in the present species, $H$. tenuis, may be also conform to this possibility, since maximal value, 2-2-3-3-2, was observed in specimens from Arimine. Therefore, the predominant formula observed in the present study, 2-2-3-2$0^{-}$, may have been derived from the maximal formula, 2-2-3-3-2, by degeneration of the phalanges of the fourth and fifth toes.

In the case of Plethodon cinereus (Plethodontidae), specimens showing the fundamental formula for the phalangeal bones in the fingers and toes accounted for more than $90 \%$ of a given population (Hanken 1983; Hanken and Dinsmore 1986). In P. neomexicanus, $97.8 \%$ of specimens showed the fundamental formula (1-2-3-2) for phalanges of the fingers, while only $2.2 \%$ showed the degenerated formula (1-2-3-1). In the toes, the frequency of the fundamental formula (1-2-3-3-2) was $68.3 \%$ and that of the degenerated formula (1-2-3-3-1) was $24.4 \%$. In the present study, in the fingers of specimens from Ashikuraji, specimens with variations of the phalangeal formula (2-2-3-1) were most frequent (32\%), in comparison to such specimens in the other species cited above.

In the present study, it is clear that degeneration of the phalangeal bones in the fingers and toes has proceeded in this species, compared to that in other salamanders. It is known that this species is one of the smallest species in the body sizes among salamanders inhabiting Japan (Sato 1943; Matsui 1987). When ecological environments are considered, this species seems to be disadvantaged on their life in various points, since they usually inhabit mountainous areas (850-1,530 $\mathrm{m}$ in altitude). Especially, low temperature and the short period of time in which they can behave actively must have affected always body growth. Furthermore, in this species, it is reported that the development of several parts of the skull is incomplete and they have few teeth (Nambu 1991). In other species such as $H$. nigrescens, similar tendencies were observed in specimens inhabiting mountainous areas, compared to those inhabiting the lowlands (Nambu 1990). Therefore. degeneration of the number of phalangeal bones may be related to retardation in body growth due to environmental factors. Nevertheless, since some morphological characteristics of $\boldsymbol{H}$. tenuis sufficiently distinguish this species from other salamanders, it is supposed that these characteristics are already fixed genetically. 


\section{References}

1) Alberch P and Gale EA. A developmental analysis of an evolutionary trend: digital reduction in amphibians. Evolution $1985 ; 39: 8-23$.

2) Dunn ER. The salamanders of Family Hynobiidae. Pro. Amer. Arts \& Sci 1923; 58:445-523.

3) Dunn ER. On the loss of the fifth toe in certain salamander. Science 1927; 66:509.

4) Dwyer CM and Hanken J. Limb skeletal variation in the Jemez Mountains salamander, Plethodon neomexicanus. Can J Zool 1989; 68:1281-1287.

5) Hanken J. High incidence of limb skeletal variants in a peripheral population of the red-backed salamander, Plethodon cinereus (Amphibia: Plethodontidae), from Nova Scotia. Can J Zool 1983; 61:1925-1931.

6) Hanken J and Dinsmore CE. Geographic variation in the limb skeleton of the red-backed salamander, Plethodon cinereus. J Herpetol 1986; 20:97-101.

7) Hasumi $M$ and Iwasawa $H$. Geological variation in the pes of salamander Hynobius lichenatus: A comparison with tetradactyl Hynobius hidamontanus and pentadactyl Hynobius nigrescens. Zoo Sci 1993; 10:1017-1027.

8) Holder N. Developmental constraints and the evolution of vertebrate digit pattern. J Theoret Biol 1983; 104: $451-475$.

9) Maruyama $T$. Digital variation in the hind legs of the salamander Hynobius lichenatus. Jpn J Herpetol 1977;
7(1):10-14. (in Japanese with English abstract)

10) Matsui M. Isozyme variation in salamanders of the nebulosuslichenatus complex of the genus Hynobius from eastern Honshu, Japan, with a description of a new species. Jpn J Herpetol 1987; 12:50-64.

11) Nakamura $K$ and Uéno S.-I. Japanese Reptiles and Amphibians in colour. Hoikusha, Osaka., 1963. (in Japanese)

12) Nambu H. Morphology of a Hynobius sp. with transparent and spindle type egg sac from the Central Japan. Zool Sci 1990; 7:1182. (Abstract)

13) Nambu H. Hynobius tenuis (Caudata, Hynobiidae) a new species of salamander from Central Japan. Zool Sci 1991; 8:991-997.

14) Sato I. A Monograph of the Tailed Batrachians of Japan. Nippon Shuppan-sha, Osaka., 1943. (in Japanese).

15) Scadding SR. Skeletal patterns in the autopodium of native and regenerated limbs of the larval axolotl, Ambystoma mexicanum. Can J Zool 1991; 69:1-6.

16) Thorn R. Les Salamanders d'Europ, d'Asie, et d'Afrique du Nord. Paul Lechevalier, Paris: Ed. Paul Lechevalie., 1968.

17) Wake DB. Comparative osteology of the plethodontid salamander, genus Aneides. J Morphol 1963; 113:77-118.

18) Wake DB. Comparative osteology and evolution of the lungless salamanders family, Plethodontidae. Mem S California Acad Sci 1966; 4:1-111.

19) Zhao E, Hu Q, Jiang $Y$ and Yang $Y$. Studies on Chinese salamanders. Contr Herpetol 1988; 4:1-67. 